\title{
Industrial Mix Antigen IgG Antibody Measurement
}

National Cancer Institute

\section{Source}

National Cancer Institute. Industrial Mix Antigen Ig G Antibody Measurement. NCI

Thesaurus. Code C130115.

A measurement of the industrial mix antigen IgG antibody in a biological specimen. 